\title{
Myocardial Function and Hemoglobin Oxygen Affinity during Hyperglycemia in the Fetal Lamb
}

\author{
H. Bard, J. C. Fouron, X. De Muylder, G. Ducharme, and J. S. Lafond \\ Cardiology and Neonatalogy Sections, Department of Pediatrics, Centre de Recherche Pédiatrique, \\ Hôpital Sainte-Justine, Université de Montréal, Montreal, Quebec
}

\begin{abstract}
To determine the effects of maternal hyperglycemia on fetal hemodynamic and cardiac function, a study was carried out on nine chronically catheterized fetal sheep. In six fetuses, glucose was infused intravenously with an initial dose of $5 \mathrm{mg} / \mathrm{kg}$ per min. Data were compared with controls. This dose was gradually increased to $16 \mathrm{mg} / \mathrm{kg}$ per min by the fifth day. The initial blood glucose was $14.7 \pm 3.0 \mathrm{mg} / \mathrm{dl}$ and increased to $54.6 \pm 16.4 \mathrm{mg} / \mathrm{dl}$ by the last day of the infusion period $(P<0.001)$. The $\mathrm{PO}_{2}$ decreased from a baseline of $20.25 \pm 3.40$ to $15.88 \pm 5.24 \mathrm{mmHg}$ $(P<0.01)$. Similarly significant decreases were also observed for the blood $\mathrm{O}_{2}$ content and $\mathrm{O}_{2}$ hemoglobin saturation: 8.5 \pm 1.7 to $6.4 \pm 2.2 \mathrm{ml} / \mathrm{dl}$ and $62.3 \pm 13.6$ to $46.1 \pm 17.6 \%$, respectively, during hyperglycemia $(P<0.01)$. The duration of the preejection period (PEP) before the start of the experiment was $45 \pm 4 \mathrm{~ms}$; a final value of $57 \pm 10 \mathrm{~ms}$ was obtained $(P<0.01)$. However, the electromechanical delay and ejection time (ET) showed no significant variation. The ratio of the PEP/ET increased from $0.31 \pm 0.04$ to $0.38 \pm 0.07(P<0.01)$ during hyperglycemia. The reticulocytes increased from $1.4 \pm 1.8$ to $3.1 \pm 2.9 \%(P<0.05)$ and the 2,3-diphosphoglycerate decreased from $4.4 \pm 1.1$ to $2.8 \pm 1.2 \mu \mathrm{mol} / \mathrm{g}$ hemoglobin $(P<0.005)$. This study demonstrated that fetal hyperglycemia depresses myocardial function in the fetal lamb. The changes in cardiac function could not be explained by the small drop in $\mathrm{O}_{2}$ saturation.
\end{abstract}

\section{Introduction}

Many clinical and pathological findings in infants of diabetic mothers are believed to be due to in utero hypoxemia. The degree of this hypoxemia is related to the magnitude of the hyperglycemia, and is possibly due to an increase in fetal oxygen consumption $(1,2)$. However, myocardial and hemodynamic disturbances, as well as changes in hemoglobin $(\mathrm{Hb})^{1} \mathrm{O}_{2}$ affinity, could also be factors causing morbidity. Indeed, congenital cardiac defects, myocardial hypertrophy, and cardiorespiratory dis-

Address reprint requests to Dr. Fouron, Cardiology Section, Hôpital Sainte-Justine, 3175 Côte Ste-Catherine, Montreal, Quebec, Canada H3T $1 \mathrm{C} 5$.

Received for publication 6 September 1985 and in revised form 7 February 1986.

1. Abbreviations used in this paper: 2,3-DPG, 2,3-diphosphoglycerate; EMD, electromechanical delay; ET, ejection time; Hb, hemoglobin; ICT, isovolumetric contraction time; $\mathrm{P}_{50}$, the oxygen pressure at $50 \%$ of the $\mathrm{Hb}$ saturation; PEP, preejection period; STI, systolic time intervals.

J. Clin. Invest.

(C) The American Society for Clinical Investigation, Inc.

0021-9738/86/07/0191/05 \$1.00

Volume 78, July 1986, 191-195 tress are known complications in infants of diabetic mothers (3-5). There have also been several controversial reports suggesting that hyperglycemia could influence the metabolism of the erythrocytes and produce changes in $\mathrm{O}_{2}$ delivery $(6,7)$.

The purpose of the current project was to investigate whether fetal hyperglycemia could, on the one hand, alter fetal myocardial function and/or, on the other hand, cause metabolic changes affecting 2,3-diphosphoglycerate (2,3-DPG) synthesis, a factor that controls $\mathrm{Hb} \mathrm{O}_{2}$ affinity. These studies were carried out using the fetal lamb as an experimental model.

\section{Methods}

Surgical preparation. Nine pregnant ewes were studied between 125 and $135 \mathrm{~d}$ of gestation. The animals were anesthetized with ketamine hydrochloride ( $3 \mathrm{mg} / \mathrm{kg}$ i.v.) alternating with sodium pentobarbital ( $2 \mathrm{mg} /$ $\mathrm{kg}$ i.v.) every 20 to $40 \mathrm{~min}$. After a local infiltration of $2 \%$ lidocaine, a subumbilical laparotomy was carried out, providing access to the gravide uterus. The technique for placement of catheters at the level of the fetal neck has been previously described (8). A micromanometer catheter (Mikrotip catheter \#7-F, model PC-470; Millar Instruments, Houston, TX) was introduced into a carotid artery and its tip was placed a few millimiters above the aortic valve. The micromanometer catheter also contained an acoustic captor which permitted the recording of a fetal phonocardiogram. In addition, a polyethylene catheter was introduced into the same carotid vessel. One external jugular vein was also cannulated for infusion purposes. Finally, three electrodes were sutured to the fetal skin. The catheters and the wires of the electrodes were passed through a subcutaneous canal and exteriorized on the maternal flank. The animal was allowed $3 \mathrm{~d}$ to recuperate. During the first $48 \mathrm{~h}$ after surgery, antibiotics (500 mg ampicillin i.v. and $500 \mathrm{mg}$ streptomycin i.m.), as well as progesterone (Delalutin, $250 \mathrm{mg}$ i.m.) were administered prophylactically.

Data collection. The fetal carotid polyethylene catheter was connected to a P23 pressure transducer (Statham Instruments, Inc., Hato Rey, Puerto Rico) allowing a continuous recording of the pressure tracing on an apparatus (RM Dynograph Recorder; Beckman Instruments, Inc., Palo Alto, CA). The transducers were placed at the level of the maternal abdomen. The fetal electrocardiogram and the aortic pressure curve obtained by the micromanometer catheter were amplified and recorded at the speed of $100 \mathrm{~mm} / \mathrm{s}$ on photosensitive paper with the aid of an Electronics for Medicine apparatus (model DR-8; Electronics for Medicine, Inc., Pleasantville, NY). This permitted the measurement of heart rate and systolic time intervals (STI). The averages of a sequence of 10 consecutive cardiac cycles were considered to be the actual values of the STI at this specific time. The following intervals were studied: the preejection period (PEP), defined as the interval between the beginning of the $Q$ wave of the electrocardiogram and the start of the rapid ascent of the aortic pressure; the electromechanical delay (EMD), defined as the interval between the beginning of the $Q$ wave and the first high frequency oscillation of the first sound obtained on the phonocardiogram; and the ejection time (ET), defined as the interval between the beginning of the ascension of the pressure curve and the nadir of the dicrotic notch. The isovolumetric contraction time (ICT) was calculated by subtracting EMD from PEP and finally the ratio PEP/ET was calculated.

The arterial fetal blood gases and $\mathrm{pH}$ were obtained on an IL217 
(Instrumentation Laboratory, Inc., Lexington, MA). The $\mathrm{O}_{2}$ content was determined by a Lex- $\mathrm{O}_{2}$-Con apparatus (Lexington Instruments Corp., Waltham, MA). The oxygen pressure at $50 \%$ of the hemoglobin saturation $\left(P_{50}\right)$ was established on a fresh blood sample using a tonometer at $37^{\circ} \mathrm{C}$ for $30 \mathrm{~min}$. The concentration of red cell 2,3-DPG was determined by the method of Keitt and blood glucose was determined by the enzymatic method of glucose oxidase.

Experimental protocol. On the fourth postoperative day the basal state was established over a 24-h period as follows: fetal arterial pressure was recorded continuously, STI were determined on six different occasions, and blood was sampled at $12-\mathrm{h}$ intervals for analysis of $\mathrm{pH}$ and blood gases. One of these samples was used for glucose, hematocrit, $\mathbf{P}_{50}$, 2,3-DPG, and reticulocyte count determinations. If all of these parameters were within normal range, the fetuses were thought to be in a satisfactory basal state and were separated into two groups. Group I consisted of six glucose-infused animals. Group II consisted of three fetuses that were injected with saline $(0.45 \mathrm{~g} / 100 \mathrm{ml})$ in the same volume and over the same period of time as group I. Group II served as a control.

In group I, $50 \%$ glucose in sterile water was injected intravenously into the fetus with a Harvard pump (Harvard Apparatus Co., Inc., S. Natick, MA), starting with an initial dose of $5 \mathrm{mg} / \mathrm{kg}$ per $\mathrm{min}$. The dose was gradually increased but was never greater than $16 \mathrm{mg} / \mathrm{kg}$ per min. The amount of total fluid administered never exceeded $2.5 \mathrm{ml} / \mathrm{kg}$ per h. The glucose perfusion lasted $5 \mathrm{~d}$. In both groups, the aortic pressure tracing was recorded continuously during the infusion period and the STI were recorded eight times for each $24-\mathrm{h}$ period. The $\mathrm{pH}$, blood gases, hematocrit, and blood sugar were analyzed at least once a day. These daily samplings caused a maximum loss of $0.8 \mathrm{ml}$ of fetal blood. During the first and the last day of the infusion $2 \mathrm{ml}$ of blood were withdrawn for reticulocyte count, $P_{50}$, and 2,3-DPG determinations.

Four of the hyperglycemic preparations were also studied $24 \mathrm{~h}$ after the end of the infusion. In all cases the fetus was delivered by cesarean section and the newborn lambs were weighed. Using the curves of Cloete (9) made it possible to extrapolate the approximate weight at the beginning of the glucose infusion and thus to reevaluate all the fetal doses administered in terms of weight. The position of the different catheters was confirmed on autopsy.

Three more experiments were added to the original protocol in order to determine if there could be changes in fetal electrolytes as well as inorganic phosphorus levels during the fetal glucose infusions carried out in this study. The electrolyte and phosphorus levels were determined under basal conditions and then followed daily during the glucose infusion. Plasma phosphorus levels were determined with the patented Inorganic Phosphorus System Assay (American Monitor Corp., Indianapolis, IN), which is based on the formation of the phosphate-molybate complex.

To compare STI changes during fetal hyperglycemia with those that occur during moderate fetal hypoxemia, data from an ongoing study was included in this study. These were from eight experiments in which the animals were prepared exactly as previously described, however, after the surgical recovery period, the pregnant ewes inspired a mixture of $10 \% \mathrm{O}_{2}, 4 \% \mathrm{CO}_{2}$, and $86 \% \mathrm{~N}_{2}$ for $1 \mathrm{~h}$, during which $\mathrm{STI}$ and blood gases were recorded at 30-min intervals. Finally, the same data was collected 30 min after the animals had resumed breathing room air.

Data analysis. In each group, comparisons between the various parameters at basal state and during the different stages of infusion were obtained by analysis of variance with repeated measurements. Data was presented as means plus or minus standard deviation. Multiple comparisons were done with Bonferroni's test. The overall significative $P$ values for these comparisons was set at 0.05 .

\section{Results}

In the hyperglycemic group the initial blood glucose, before the start of the experiment, was $14.7 \pm 3.0 \mathrm{mg} / \mathrm{dl}$ and on the last day of the infusion reached $54.6 \pm 16.4 \mathrm{mg} / \mathrm{dl}(P<0.001)$. The glycemia, blood gases, and $\mathrm{Hb}$ saturation are presented in Table I. A significant change was observed during the glucose infusion for all three parameters $(P<0.01)$. Multiple comparisons showed that they started to decrease on the first day of infusion. Changes were also observed for the $\mathrm{PCO}_{2}(P<0.05)$, which increased to a maximum on the third day of infusion $(39.34 \pm 3.41$ to $47.48 \pm 5.52 \mathrm{mmHg}$ ). There was no significant changes in acidbase balance during the experiment. For the control group, the initial blood glucose was $17.5 \pm 0.70 \mathrm{mg} / \mathrm{dl}$ and did not change significantly throughout the infusion period. Blood gas and $\mathrm{pH}$ values for this group remained within physiological limits.

Changes in the indices of myocardial function at the end of glucose infusion are also included in Table I. The duration of the PEP before the start of the experiment was $45 \pm 4 \mathrm{~ms}$. During

Table I. Changes in Fetal Arterial Blood Gases, Hemoglobin Oxygen Affinity, and Systolic Time Intervals during Fetal Saline and Glucose Infusions

\begin{tabular}{|c|c|c|c|c|c|c|}
\hline & $\begin{array}{l}\text { Prior to saline } \\
\text { infusion }\end{array}$ & $\begin{array}{l}\text { Day } 5 \text { end of } \\
\text { experiment }\end{array}$ & $\begin{array}{l}\text { Prior to glucose } \\
\text { infusion }\end{array}$ & $\begin{array}{l}\text { Day } 1 \text { of } \\
\text { infusion }\end{array}$ & $\begin{array}{l}\text { Day } 3 \text { of } \\
\text { infusion }\end{array}$ & $\begin{array}{l}\text { Day } 5 \text { end of } \\
\text { experiment }\end{array}$ \\
\hline $\mathrm{PO}_{2}(\mathrm{mmHg})$ & $16.4 \pm 0.4$ & $17.3 \pm 4.6$ & $20.3 \pm 3.4$ & $18.0 \pm 3.2$ & $18.2 \pm 5.5$ & $15.9 \pm 5.2^{*}$ \\
\hline $\mathrm{PCO}_{2}(\mathrm{mmHg})$ & $38.6 \pm 1.4$ & $36.3 \pm 8.6$ & $39.3 \pm 3.4$ & $44.8 \pm 2.4$ & $47.5 \pm 5.5$ & $45.2 \pm 1.4 \ddagger$ \\
\hline pH & $7.43 \pm 0.02$ & $7.39 \pm 0.05$ & $7.41 \pm 0.03$ & $7.39 \pm 0.16$ & $7.35 \pm 0.02$ & $7.38 \pm 0.01$ \\
\hline $\mathrm{HbO}_{2}(\%)$ & $76.5 \pm 2.1$ & $71.5 \pm 0.7$ & $62.3 \pm 13.6$ & $60.4 \pm 12.0$ & $58.7 \pm 15.1$ & $46.1 \pm 17.6^{*}$ \\
\hline $\mathrm{O}_{2}$ content $(\mathrm{ml} / \mathrm{dl})$ & $13.2 \pm 0.6$ & $11.4 \pm 0.7$ & $8.5 \pm 1.7$ & $7.96 \pm 0.9$ & $7.0 \pm 2.3$ & $6.4 \pm 2.2^{*}$ \\
\hline Reticulocyte (\%) & $0.6 \pm 0.2$ & $0.3 \pm 0.2$ & $1.4 \pm 1.8$ & - & - & $3.1 \pm 2.9 \ddagger$ \\
\hline Hematocrit (\%) & $38.6 \pm 0.6$ & $35.7 \pm 2.5$ & $30.2 \pm 2.3$ & $28.6 \pm 1.4$ & $30.3 \pm 5.9$ & $30.6 \pm 2.1$ \\
\hline 2,3-DPG $(\mu \mathrm{mol} / \mathrm{g} \mathrm{Hb})$ & $3.2 \pm 0.4$ & $3.1 \pm 0.1$ & $4.4 \pm 1.1$ & - & - & $2.8 \pm 1.2 \S$ \\
\hline $\mathrm{P}_{50}(m m H g)$ & $16.5 \pm 0.5$ & $17.1 \pm 0.8$ & $19.4 \pm 1.1$ & - & - & $19.8 \pm 1.8$ \\
\hline Glucose $(m g / d l)$ & $17.5 \pm 0.7$ & $19.0 \pm 0$ & $14.7 \pm 5.0$ & $23.0 \pm 2.5$ & $35.0 \pm 6.6$ & $54.6 \pm 16.4 \S$ \\
\hline PEP (msec) & $50.2 \pm 4.7$ & $51.1 \pm 2.4$ & $45.0 \pm 4.1$ & $48.2 \pm 6.1$ & $51.7 \pm 8.3$ & $57.0 \pm 1.0^{*}$ \\
\hline EMD (msec) & $25.3 \pm 4.5$ & $26.6 \pm 9.1$ & $26.0 \pm 6.0$ & $25.5 \pm 6.1$ & $25.9 \pm 5.3$ & $25.0 \pm 5.1$ \\
\hline $\mathrm{ET}$ (msec) & $156.9 \pm 9.9$ & $150.6 \pm 13.2$ & $148.0 \pm 8.3$ & $145.9 \pm 7.6$ & $154.9 \pm 7.8$ & $158.0 \pm 4.2$ \\
\hline $\mathbf{R}-\mathbf{R}(\mathrm{msec})^{\| \prime}$ & $391.6 \pm 34.4$ & $406.8 \pm 25.5$ & $330.0 \pm 3.2$ & $322.0 \pm 23.7$ & $351.0 \pm 45.7$ & $354.0 \pm 1.2$ \\
\hline PEP/ET (msec) & $0.32 \pm 0.02$ & $0.33 \pm 0.01$ & $0.31 \pm 0.04$ & $0.32 \pm 0.05$ & $0.34 \pm 0.05$ & $0.38 \pm 0.07^{*}$ \\
\hline
\end{tabular}

${ }^{*} P<0.01 . \ddagger P<0.05 . \quad \S P<0.005$, compared with pre-glucose infusion. " $\mathrm{R}-\mathrm{R}$, the time interval between $\mathrm{R}$ waves on the electrocardiogram. 
the glucose infusion a significant variation of PEP was observed $(P<0.01)$ and a final value of $57 \pm 10 \mathrm{~ms}$ was obtained. Subsequently, multiple comparisons demonstrated that this increase was significant after the third day of infusion. The EMD and ET showed no significant variation. On the other hand, the ratio PEP/ET increased during the experiment, going from $0.31 \pm 0.04$ to $0.38 \pm 0.07(P<0.01)$. This change was already significant on the first day of infusion. No variation was noted for the same parameters in the saline-infused animals.

The PEP showed a significant correlation with glycemia $(r$ $=0.65$ ). On the other hand, there was no relationship between the increase in PEP and the changes in $\mathrm{O}_{2}$ content. The relationship of STI and glycemia are shown in Fig. 1. This figure illustrates the fact that ICT was the PEP component most affected by hyperglycemia. There were no significant changes noted in heart rate and arterial blood pressure in either group of fetuses. Table II demonstrates the changes in STI during fetal hypoxemia. The hypoxemia without acidosis caused a shortening of the PEP and a decrease of the PEP/ET ratio.

The changes in red cell parameters are included in Table I. The reticulocytes increased significantly while the hematocrit remained unchanged. The hemoglobin oxygen affinity did not change during the infusion, however, the red blood cell 2,3DPG decreased significantly. The same values studied in the control group showed no significant modification. In the four preparations that were allowed to recover for 24-h after the end
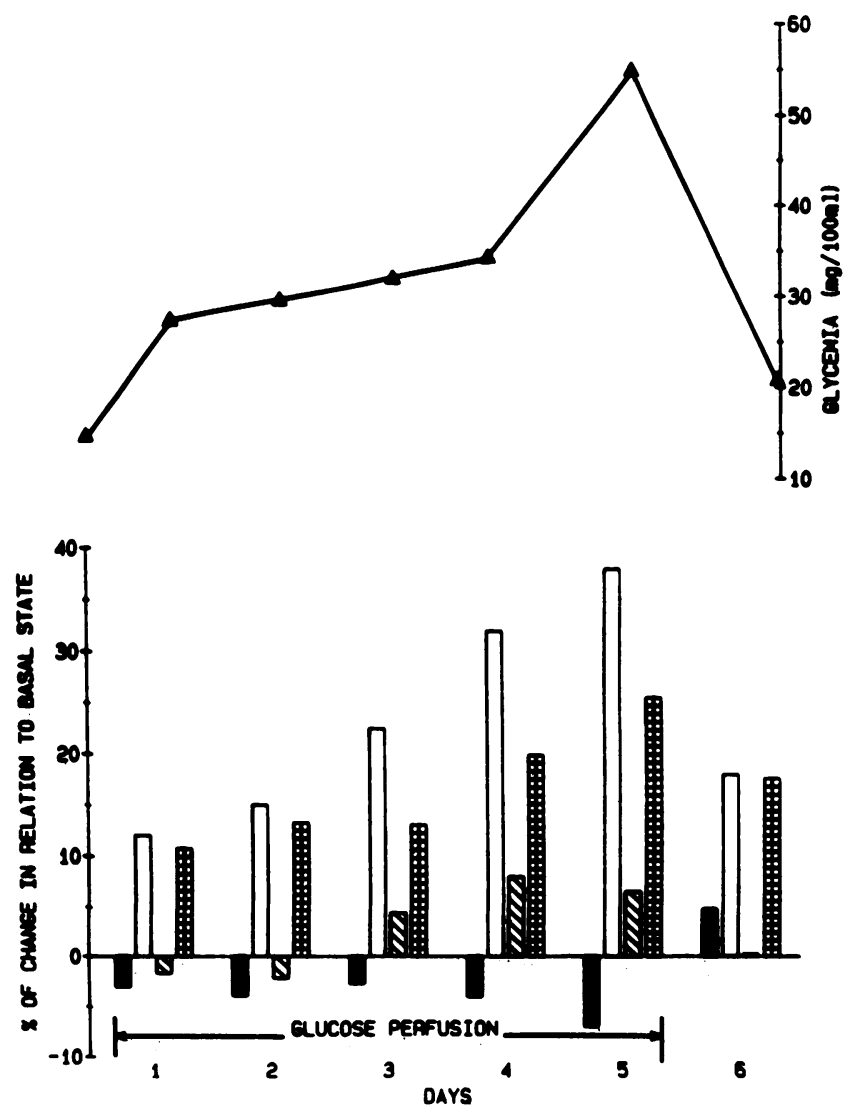

Figure 1. The lower part of this figure demonstrates the change in STI during glucose infusion in relation to the basal state. The upper part shows the concomitant changes in the mean levels of glycemia. $\square$, EMD; ㅁ, ICT; $₫$, ET; 曲, PEP/ET. of the experiment, $\mathrm{O}_{2}$ content, $\mathrm{PO}_{2}$, and $\mathrm{PCO}_{2}$, as well as STI, returned to their preinfusion values.

There were no changes in sodium or potassium concentrations during the glucose infusions. The sodium levels before and at the end of the experiments were $142.3 \pm 2.5$ and $145 \pm 3.5 \mathrm{meq} /$ liter, respectively, while potassium levels were $4.6 \pm 0.5$ and $4.5 \pm 0.3 \mathrm{meq} / \mathrm{liter}$. Inorganic phosphorus did not change significantly during the $5 \mathrm{~d}$ of glucose infusions. The basal value was $8.2 \pm 1.9 \mathrm{mg} / \mathrm{dl}$; on the third day, $7.8 \pm 0.7 \mathrm{mg} / \mathrm{dl}$; and finally, on the fifth day, $7.0 \pm 1.5 \mathrm{mg} / \mathrm{dl}$.

\section{Discussion}

The infusion of glucose in a peripheral vein of the fetus was an attempt to reproduce the conditions that occur in the fetus of a diabetic mother. Fetal hyperglycemia stimulates the pancreas and causes a rise in fetal insulin secretion (10). Hyperglycemia and secondary hyperinsulinemia of the fetus, consequences of maternal hyperglycemia, could be the major elements in the pathophysiology of the fetus of the diabetic mother $(11,12)$.

To investigate the circulatory and myocardial status of the fetuses, in addition to the usual cardiovascular parameters such as arterial pressure and heart rate, the STI were monitored. For several years STI have been used in the adult as an index of myocardial function (13) and have potential usefulness as indicators of the functional integrity of the fetal cardiovascular system (14). In this study, as in others (2), no change was observed in arterial pressure and heart rate during the glucose infusion. However, significant variations were noted in the STI, the most striking being the prolongation of the PEP. In theory, lengthening of the PEP can result from either an increase in the ventricular afterload, a decrease in the preload, an intramyocardial conducting delay, a loss of myocardial contractility, or a combination of all these different factors. As mentioned above, the arterial pressure remained stable throughout the experiments, eliminating changes of afterload as contributing factors. The preload or venous return to the ventricles have not been measured in this study. However, Philipps et al. (2), in a similar experimental preparation, reported no alteration in umbilical blood flow, which represents, in fetal life, $50 \%$ of the venous return to the heart.

In the absence of any sign of intraventricular conduction disturbances expressed by the stable EMD, the only variable left to explain the significant lengthening of the PEP is a decrease in myocardial contractility. This finding is in accordance with the observations of Murata et al. (15) who noted a prolongation of the PEP in 41 fetuses of diabetic pregnancies and related their findings to the excessive weight of the newborns. In diabetic adults without any signs of myocardial ischemia or vascular disease, prolongation of PEP and increase of PEP/ET have been demonstrated with chronic hyperglycemia (16-18). These observations, along with the experimental findings in alloxantreated dogs (19), confirm the hypothesis that chronic hyperglycemia could disturb the cellular composition and the function of the heart independently of any vascular effect. In our study, which covered a relatively short period of gestation time, this complication had no obvious consequences on fetal well-being. The effects on umbilical circulation and fetal oxygenation of a more prolonged state of fetal hyperglycemia remain to be determined.

Blood samples were purposely withdrawn from ascending aorta in order to obtain a reliable assessment of $\mathrm{O}_{2}$ content in 
Table II. Changes in Fetal Arterial Blood Gases and Systolic Time Intervals during a Moderate Hypoxemia

\begin{tabular}{lcccc}
\hline & Basal & 30 min & 60 min & $\begin{array}{c}30 \text { min after end } \\
\text { of experiment }\end{array}$ \\
\hline $\mathrm{PO}_{2}(\mathrm{mmHg})$ & $19.7 \pm 2.4$ & $13.6 \pm 2.3^{*}$ & $13.9 \pm 2.5^{*}$ & $21.4 \pm 1.9$ \\
$\mathrm{PCO}_{2}(\mathrm{mmHg})$ & $41.4 \pm 6.2$ & $34.7 \pm 6.7^{*}$ & $34.4 \pm 7.2^{*}$ & $37.0 \pm 6.7^{*}$ \\
$\mathrm{pH}$ & $7.40 \pm 0.02$ & $7.40 \pm 0.06$ & $7.39 \pm 0.06$ & $7.39 \pm 0.06$ \\
$\mathrm{PEP}(\mathrm{ms})$ & $49.1 \pm 6.6$ & $43.5 \pm 7.2^{*}$ & $42.5 \pm 5.4^{*}$ & $48.7 \pm 6.2$ \\
$\mathrm{EMD}(\mathrm{ms})$ & $32.34 \pm 7.32$ & $31.91 \pm 7.35$ & $29.85 \pm 3.27$ & $33.85 \pm 2.70$ \\
$\mathrm{ET}(\mathrm{ms})$ & $154.1 \pm 6.7$ & $156.3 \pm 9.6$ & $154.9 \pm 9.2$ & $159.1 \pm 18.7$ \\
$\mathrm{R}-\mathrm{R}(\mathrm{ms})$ & $350.8 \pm 25.5$ & $380.2 \pm 63.7$ & $382.5 \pm 46.5$ & $346.4 \pm 48.2$ \\
PEP/ET & $0.31 \pm 0.03$ & $0.30 \pm 0.05^{*}$ & $0.27 \pm 0.03^{*}$ & $0.32 \pm 0.01$ \\
\end{tabular}

* $P<0.05$ compared with basal.

the coronary arteries. A moderate hypoxemia was noted during hyperglycemia. This decrease in arterial $\mathrm{O}_{2}$ content is not likely to be solely responsible for the signs of myocardial dysfunction observed. Indeed, in the group of eight fetal lambs with isolated hypoxemia, contrary to the effects seen with fetal hyperglycemia, a shortening of PEP was noted. The same observation has been made in the fetal lamb by others (20) and is believed to be due to catecholamine effects. Only severe fetal hypoxia with acidosis causes prolongation of PEP (14). The $\mathrm{pH}$ of our animals was always normal. Previous work using the fetal lamb has demonstrated that a pronounced fetal hyperglycemia can cause not only hypoxemia, but lactic acidosis and eventual fetal demise (21) as well. In the present study, the maximum levels of glycemia attained were below those causing acidosis and have been previously shown to have little effect on $\mathrm{pH}(2)$.

Downing et al. showed that hyperglycemia in the insulindeficient diabetic lamb induced by alloxan had no effect on myocardial function (22). However, when insulin was given, a fall in stroke volume occurred. The results of our study do not contradict these findings. It could well be that in our animals a combination of hyperglycemia, the presence of insulin, and moderate hypoxia caused an increase in PEP. This would support the concept that insulin reduces the inotropic sensitivity of the heart to catecholamines (23).

During periods of parenteral nutrition which induce severe hypophosphatemia, reductions in 2,3-DPG and ATP are known to occur (24). In the present study, inorganic phosphorus remained within the levels considered normal for fetal sheep (25). Sodium and potassium also remained unchanged during these experiments. This lack of change can be explained by the fact that inorganic phosphorus is thought to be actively transported across the placenta to the fetus (26), while there is rapid diffusion of electrolytes and water across the placenta (27). Philipps (2), using a similar protocol, showed that serum solids remained unchanged throughout his experiments.

An increase in glucose concentration could possibly result in metabolic alterations in the erythrocytes, causing the observed decrease in 2,3-DPG similar to that described in the human red cell (6). The fact that this finding had no detectable effect on $\mathbf{P}_{50}$ could be related to the species used in the experiment. In a previously reported study it was observed that the fetal level of 2,3DPG was $4.43 \pm 1.53$ (SD) $\mu \mathrm{mol} / \mathrm{g} \mathrm{Hb}$ and was not influenced by gestational age (28). In that same study it was demonstrated that after $120 \mathrm{~d}$ of gestation $P_{50}$ increases $\sim 1 \mathrm{mmHg}$ every $7 \mathrm{~d}$, because of the switchover from fetal to adult $\mathrm{Hb}$ synthesis. Thus, the fact that $P_{50}$ did not change in the present study could be easily explained: the effect of the decrease in 2,3-DPG was balanced by a small increase in adult $\mathrm{Hb}$. A similar proportional decrease in 2,3-DPG in the human fetus could have a more significant effect on $\mathrm{Hb}$ oxygen association.

\section{Acknowledgments}

We wish to thank Marie-Thérèse Rabeau, Janie Prosmanne, and François Rivard for their excellent technical assistance and Sylvie Tassé for the preparation of this manuscript.

This work was supported in part by the Medical Research Council of Canada, the Quebec Heart Foundation, Fonds de la Recherche en Santé du Québec, and Fondation Justine-Lacoste-Beaubien.

\section{References}

1. Philipps, A. F., J. W. Dubin, P. J. Matty, and J. R. Raye. 1982. Arterial hypoxemia and hyperinsulinemia in the chronically hyperglycemic fetal lamb. Pediatr. Res. 16:653-658.

2. Philipps, A. F., P. J. Porte, S. Stabinsky, T. S. Rosenkrantz, and J. R. Raye. 1984. Effects of chronic fetal hyperglycemia upon oxygen consumption in the ovine uterus and conceptus. J. Clin. Invest. 74:279286.

3. Hirschfeld, S. S., A. A. Fanaroff, and I. R. Merkatz. 1979. Cardiovascular abnormalities in infants of diabetic mothers. In The Diabetic Pregnancy. A Perinatal Perspective. I. R. Merkatz, and P. A. J. Adam, editors. Grune \& Stratton Inc., New York. 249-260.

4. Breitweser, J. A., R. A. Meyer, M. A. Sperling, R. C. Tsang, and S. Kaplan. 1980. Cardiac septal hypertrophy in hyperinsulinemic infants. J. Pediatr. 96:535-539.

5. Mace, S., S. S. Hirschfeld, T. Riggs, A. A. Fanaroff, and I. R. Merkatz. 1979. Echocardiographic abnormalities in infants of diabetic mothers. J. Pediatr. 95:1013-1019.

6. Travis, S. F., A. D. Morrison, R. S. Clements, Jr., A. I. Winegrad, and F. A. Oski. 1971. Metabolic alterations in the human erythrocyte produced by increases in glucose concentration. J. Clin. Invest. 50:21042111.

7. Ditzel, J. 1976. Oxygen transport impairment in diabetes. Diabetes. 25(Suppl. 2):832-838.

8. Fouron, J. C., Y. Korcaz, and B. Leduc. 1975. Cardiovascular changes associated with fetal breathing. Am. J. Obstet. Gynecol. 123: 868-876.

9. Cloete, J. M. 1939. Prenatal growth in the merino sheep. Onderstepoort J. Vet. Res. 13:417-547.

10. Philipps, A. F., B. S. Carson, G. Meschia, and F. C. Battaglia. 1978. Insulin secretion in fetal and newborn sheep. Am. J. Physiol. 235: E467-E474. 
11. Karlsson, K., and I. Kjellmer. 1971. The outcome of diabetic pregnancies in relation to the mother's blood sugar level. Am. J. Obstet. Gynecol. 112:213-220.

12. Gabbe, S. G. 1978. Application of scientific rationale to the management of the pregnant diabetic. Semin. Perinatol. 2:361-371.

13. Weissler, A. 1977. Current concepts in cardiology: systolic time intervals. N. Engl. J. Med. 296:321-324.

14. Murata, Y. 1982. Advances on the horizon. Clin. Perinatol. 9: 433-441.

15. Murata, Y., and P. Schmidt. 1977. The pre-ejection phase of the fetal cardiac cycle in diabetic patients: antepartum evaluation. Gynecol. Invest. 8:108. (Abstr.)

16. Oto, A., A. Oram, A. Karamehmetoglu, F. Telatar, and S. Akalin. 1982. Non-invasive assessment of left ventricular function in diabetics without clinical heart disease. Acta Diabetol. Lat. 19:49-53.

17. Uusitupa, M., O. Siitonen, A. Aro, T. Korhonen, and K. Pyörälä. 1983. Effect of correction of hyperglycemia on left ventricular function in non-insulin-dependent (type 2) diabetics. Acta Med. Scand. 213:363368.

18. Cellina, G., G. Lo Cicero, A. Brina, and A. Zanchetti. 1983. Reversible alteration of myocardial function in gestational diabetes. Eur. Heart J. 4:59-63.

19. Regan, T. J., P. O. Ettinger, M. I. Khan, M. U. Jesrani, M. M. Lyons, H. A. Oldewurtel, and M. Weber. 1974. Altered myocardial function and metabolism in chronic diabetes mellitus without ischemia in dogs. Circ. Res. 35:222-237.

20. Organ, L. W., J. E. Milligan, J. W. Goodwin, and M. J. C. Bain.
The pre-ejection period of the fetal heart: response to stress in the term fetal lamb. Am. J. Obstet. Gynecol. 115:377-386.

21. Robillard, J. E., C. Sessions, R. L. Kennedy, and F. G. Smith, Jr. 1978. Metabolic effects of constant hypertonic glucose infusion in well-oxygenated fetuses. Am. J. Obstet. Gynecol. 130:199-203.

22. Downing, S. E., J. C. Lee, and J. C. Werner. 1981. Effects of insulin on ventricular function in diabetic lambs with acidosis. Am. J. Physiol. 241:H401-H407.

23. Nudel, D. B., J. C. Lee, and S. E. Downing. 1977. Reciprocal inhibition of cardiac responses to norepinephrine and insulin. Am. J. Physiol. 233:H665-H669.

24. Travis, S. F., H. J. Sugerman, R. L. Ruberg, S. J. Dudrick, M. Delivoria-Papadopoulos, L. D. Miller, and F. A. Oski. 1971. Alterations of red-cell glycolytic intermediates and oxygen transport as a consequence of hypophosphatemia in patients receiving intravenous hyperalimentation. N. Engl. J. Med. 285:763-768.

25. Smith, F. G., Jr., P. Alexander, R. M. Buckle, H. G. Britton, and D. A. Nixon. 1972. Parathyroid hormone in foetal and adult sheep: the effect of hypocalcaemia. J. Endocrinol. 53:339-348.

26. Brunette, M. G., and S. Allard. 1985. Phosphate uptake by syncytial brush border membranes of human placenta. Pediatr. Res. 19: 1179-1182.

27. Meschia, G., F. C. Battaglia, and P. D. Bruns. 1967. Theoretical and experimental study of transplacental diffusion. J. Appl. Physiol. 22: 1171-1178.

28. Bard, H., J.-C. Fouron, J. E. Robillard, A. Cornet, and M. A. Soukini. 1978. Red cell oxygen affinity in fetal sheep: role of 2,3-DPG and adult hemoglobin. J. Appl. Physiol. 45:7-10. 